University of New Orleans

ScholarWorks@UNO

3-1985

\title{
Explicit equations for the polarizing angles of a high-reflectance substrate coated by a transparent thin film
}

R. M.A. Azzam

University of New Orleans, razzam@uno.edu

Follow this and additional works at: https://scholarworks.uno.edu/ee_facpubs

Part of the Electrical and Electronics Commons, and the Optics Commons

\section{Recommended Citation}

R. M. A. Azzam, "Explicit equations for the polarizing angles of a high-reflectance substrate coated by a transparent thin film," J. Opt. Soc. Am. A 2, 480-482 (1985)

This Article is brought to you for free and open access by the Department of Electrical Engineering at ScholarWorks@UNO. It has been accepted for inclusion in Electrical Engineering Faculty Publications by an authorized administrator of ScholarWorks@UNO. For more information, please contact scholarworks@uno.edu. 


\title{
Explicit equations for the polarizing angles of a high-reflectance substrate coated by a transparent thin film
}

\author{
R. M. A. Azzam \\ Department of Electrical Engineering, University of New Orleans, Lakefront, New Orleans, Louisiana 70148 \\ Received July 16, 1984; accepted October 30, 1984

\begin{abstract}
Simple explicit equations are derived that determine the angles of incidence at which the parallel and perpendicular polarization components of light are extinguished on reflection from a transparent film coating a high-reflectance (metallic) substrate. The polarizing angles obtained from our approximate expressions are in excellent agreement with those determined by iterative numerical solution of the exact nonlinear equations that govern such angles. For the approximation to be valid, the intensity reflectance of the film-substrate interface, evaluated at the critical angle of the film-ambient interface, must exceed 0.5 .
\end{abstract}

Polarization of monochromatic or quasi-monochromatic light by reflection from a dielectric or metallic substrate coated by a dielectric thin film is well known. ${ }^{1}$ For given optical constants of the (transparent) film and (absorbing) substrate, the required angles of incidence for zero reflection of the parallel $(p)$ and perpendicular $(s)$ polarizations are determined by transcendental equations that can be solved only iteratively. ${ }^{2}$

In this communication, we derive simple explicit equations for the $p$ - and $s$-polarizing angles of a film-substrate system. The equations are approximate but accurate when the substrate reflectance is sufficiently high. High-reflectance (metallic) substrates (e.g., Ag or $\mathrm{Al}$ ) are needed to achieve high throughput for the unextinguished component and hence a more efficient polarizer. ${ }^{2}$

The basis for the approximation can be ascertained by considering Fig. 1. In this figure, we plot the Fresnel-intensity reflectances $^{3}$

$$
\mathcal{R}_{i j \nu}=\left|r_{i j \nu}\right|^{2}
$$

of the ambient-film $(i j=01)$ and film-substrate $(i j=12)$ interfaces for the parallel $(\nu=p)$ and perpendicular $(\nu=s)$ polarizations as functions of the grazing angle of incidence $\theta$ between the light beam and the reflecting surface. $[\theta=(\pi / 2)$ $-\phi$, where $\phi$ is the usual angle of incidence between the beam direction and the surface normal.] The data of Fig. 1 are for a representative case of an $\mathrm{Al}$ substrate of complex refractive index ${ }^{4} N_{2}=1.212-j 6.924$ coated by a transparent film $\left(\mathrm{Al}_{2} \mathrm{O}_{3}\right)$ of refractive index $N_{1}=1.6$. Light of wavelength $\lambda$ $=6328 \AA$ (from a He-Ne laser) is assumed to be incident upon this film-substrate system from air or from vacuum $\left(N_{0}=\right.$ 1).

Suppression of a given ( $p$ or $s$ ) polarization on reflection is possible by interference in the thin film at the angle of incidence that makes the ambient-film and film-substrate interface reflectances equal, 2,5 i.e., when

$$
\mathcal{R}_{01 \nu}=\mathcal{R}_{12 \nu}, \quad \nu=p \text { or } s .
$$

The points of intersection of the $p$ and $s$ pairs of reflectance curves, denoted by $\mathrm{P}$ and $\mathrm{S}$, respectively, determine the corresponding polarizing angles $\theta_{p}$ and $\theta_{s}$, as shown in Fig. 1.
Two observations regarding Fig. 1 make the derivation of accurate explicit equations for the polarizing angles possible:

(1) The grazing polarizing angles are small (of the order of a few degrees for a high-reflectance metal substrate ${ }^{2,5}$ ).

(2) $\mathcal{R}_{12 p}$ and $\mathcal{R}_{12 s}$ stay virtually constant with $\theta$ (they change imperceptibly, by $<0.2 \%$ ), as $\theta$ increases from 0 to $10^{\circ}$.

Correspondingly, two sensible approximations can be made. The first is to replace the exact Fresnel eq iations of $\mathcal{R}_{01 \nu}(\nu$ $=p, s$ ) by quadratic Taylor-series expansions valid about $\theta$ $=0$. The second is to set

$$
\mathcal{R}_{12 \nu}\left(\theta_{\nu}\right) \cong \mathcal{R}_{12 \nu}(0), \quad \nu=p, s .
$$

The first three terms of the Taylor-series expansion of the ambient-film Fresnel (amplitude-reflection) coefficients, valid near grazing incidence, can be written as ${ }^{6}$

$$
\begin{aligned}
& r_{01 p}=-1+2 E(E-1)^{-1 / 2} \theta-2 E^{2}(E-1)^{-1} \theta^{2}+\ldots, \\
& r_{01 s}=-1+2(E-1)^{-1 / 2} \theta-2(E-1)^{-1} \theta^{2}+\ldots,
\end{aligned}
$$

where

$$
E=N_{1}^{2} / N_{0}^{2}
$$

and $N_{0}, N_{1}$ are the ambient and film refractive indices, respectively. By squaring Eqs. (4), the corresponding intensity reflectances are obtained:

$$
\begin{aligned}
& \mathcal{R}_{01 p}=1-4 E(E-1)^{-1 / 2} \theta+8 E^{2}(E-1)^{-1} \theta^{2}, \\
& \mathcal{R}_{01 s}=1-4(E-1)^{-1 / 2} \theta+8(E-1)^{-1} \theta^{2},
\end{aligned}
$$

where terms including $\theta^{n}(n>2)$ have been dropped.

At the polarizing angles, $\mathcal{R}_{01 p}$ and $\mathcal{R}_{01 s}$, which appear on the left-hand sides of Eqs. (6a) and (6b), can be replaced by $\mathcal{R}_{12 p}(0)$ and $\mathcal{R}_{12 s}(0)$, respectively, according to Eqs. (2) and (3). Next, quadratic Eqs. (6) are solved for $\theta$ to give

$$
\theta_{p a 2}=\frac{(E-1)^{1 / 2}}{4 E}\left\{1-\left[2 \mathscr{R}_{12 p}(0)-1\right]^{1 / 2}\right\},
$$




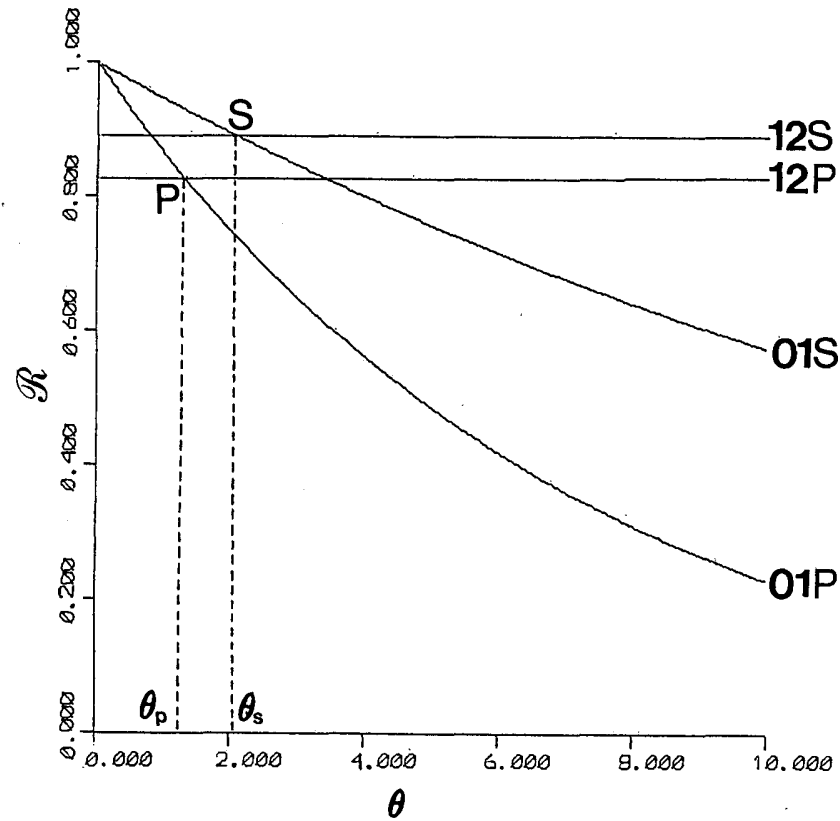

Fig. 1. Intensity reflectances $\mathcal{R}$ of the ambient-film (01) and filmsubstrate ${ }^{12}$ interfaces for the $p$ and $s$ polarizations as functions of the grazing-incidence angle $\theta$ in degrees. Reflection of $\mathrm{He}-\mathrm{Ne}$ laser light $(\lambda=6328 \AA)$ in air $\left(N_{0}=1\right)$ by an $\mathrm{Al}_{2} \mathrm{O}_{3}\left(N_{1}=1.6\right)$ film coating an $\mathrm{Al}$ $\left(N_{2}=1.212-j 6.924\right)$ substrate is assumed. The points of intersection $\mathrm{P}$ and $\mathrm{S}$ determine the polarizing angles $\theta_{p}$ and $\theta_{s}$, respectively.

$$
\theta_{s a 2}=\frac{(E-1)^{1 / 2}}{4}\left\{1-\left[2 \mathcal{R}_{12 s}(0)-1\right]^{1 / 2}\right\} .
$$

Equations (7) are the desired explicit equations for the $p$ - and $s$-polarizing angles in radians. The subscript $a 2$ refers to the quadratic approximation used.

Expressing Eqs. (7) in degrees and as functions of the film refractive index $N_{1}$ (and assuming an air or vacuum ambient $N_{0}=1$ ) yields

$$
\begin{aligned}
\theta_{p a 2} & =(45 / \pi) \frac{\left(N_{1}^{2}-1\right)^{1 / 2}}{N_{1}^{2}}\left\{1-\left[2 \mathscr{R}_{12 p}(0)-1\right]^{1 / 2}\right\}, \\
\theta_{s a 2} & =(45 / \pi)\left(N_{1}^{2}-1\right)^{1 / 2}\left\{1-\left[2 \mathcal{R}_{12 s}(0)-1\right]^{1 / 2}\right\} .
\end{aligned}
$$

In Eqs. (7) and (8), $\mathcal{R}_{12 \nu}(0)$, the Fresnel-intensity reflectances for the $\nu=p, s$ polarizations of the film-substrate, are functions of $N_{1}$ and are evaluated at external grazing incidence $\theta$ $=0$ (i.e., when light is refracted in the film at the critical angle of the film-ambient interface).

For the $\mathrm{Al}_{2} \mathrm{O}_{3}-\mathrm{Al}$ film-substrate system, with the optical constants at $\lambda=6328 \AA$ as given above, we calculate $\mathscr{R}_{12 p}(0)$ $=0.8261$ and $\mathscr{R}_{12 s}(0)=0.8908$. Substitution of these reflectances and $N_{1}=1.6$ into Eqs. (8) gives the following $a p$ proximate polarizing angles:

$$
\theta_{p a 2}=1.344^{\circ}, \quad \theta_{s a 2}=2.073^{\circ} .
$$

The exact polarizing angles, obtained by numerical iteration ${ }^{7}$ (to bring $\left|r_{01 \nu} / r_{12 v}\right|$ to within $<10^{-6}$ of 1 ), are given by

$$
\theta_{p e}=1.335^{\circ}, \quad \theta_{s e}=2.070^{\circ} \text {. }
$$

The excellent agreement between the approximate and exact polarizing angles verifies the high accuracy of Eqs. (8).

From Eqs. (7) and (8) it is evident that the condition

$$
\mathscr{R}_{12 \nu}(0)>0.5 \quad \nu=p, s
$$

must be satisfied for the approximate equations to yield meaningful real answers. We have verified that the accuracy of the approximation improves steadily as $\mathcal{R}_{12 \nu}(0)$ increases above this lowest limit of 0.5 . The polarizing angles from the approximate and exact equations agree to within a few percent for $\mathscr{R}_{12 \nu}(0)>0.7$. This condition is met readily when a high-reflectance metal substrate is used.

For further illustration, the exact and approximate $p$ - and $s$-polarizing angles are calculated for a system that consists

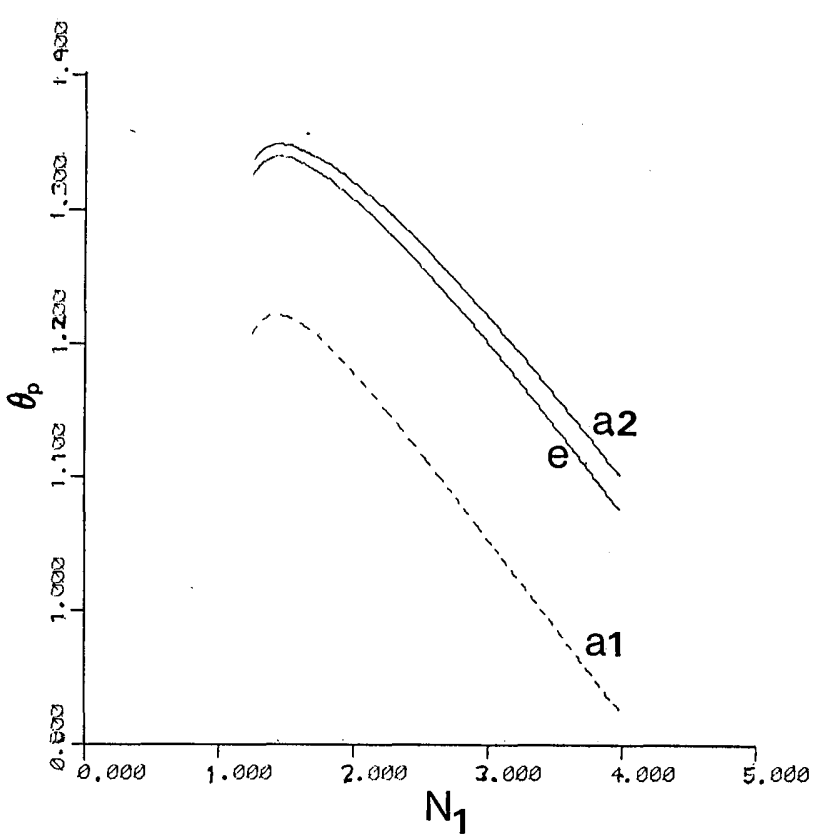

Fig. 2. Approximate (a2) and exact (e) $p$-polarizing angles $\theta_{p}$ (in degrees) as functions of the refractive index $N_{1}$ of a transparent film on an Al substrate $\left(N_{2}=1.212-j 6.924\right)$. The dashed curve $a 1$ represents the linear (instead of parabolic, $a 2$ ) approximation to the polarizing angle.

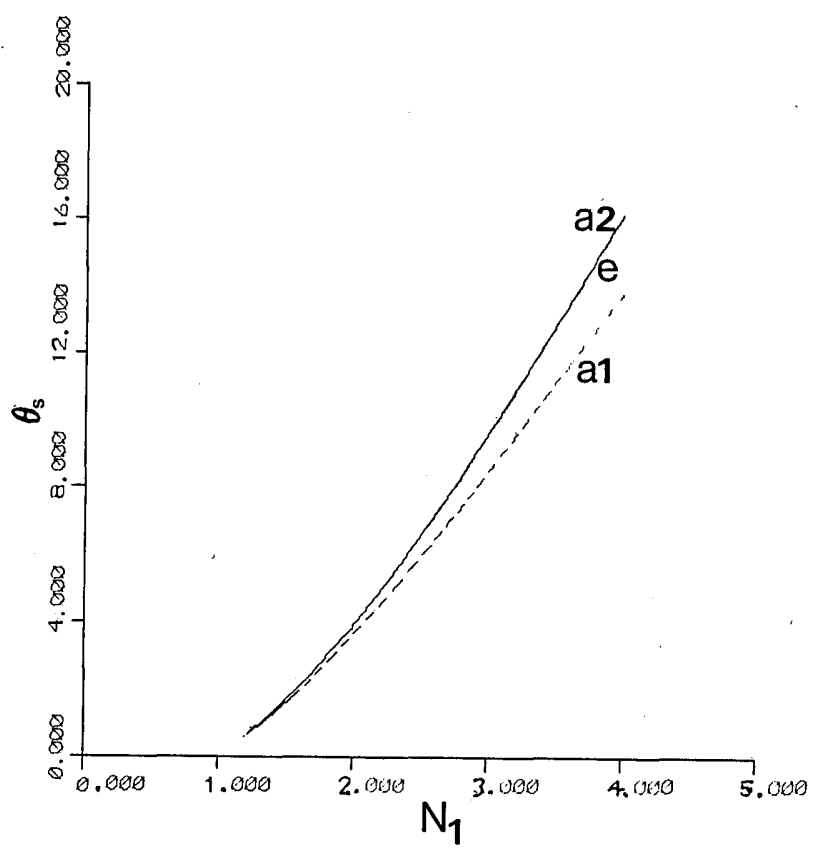

Fig. 3. Same as Fig. 2 but for the $s$ polarization. 
Table 1. Comparison between the Approximate and Exact $p\left(\theta_{p a 2}, \theta_{p e}\right)$ and $s\left(\theta_{s a 2}, \theta_{s e}\right)$ Grazing Polarizing Angles of Incidence of Transparent Films on Metal Substrates ${ }^{a}$

\begin{tabular}{|c|c|c|c|c|c|c|c|}
\hline $\begin{array}{c}\text { Substrate } \\
(\lambda)\end{array}$ & $N_{1}$ & $\mathcal{R}_{12 p}(0)$ & $\theta_{p a 2}$ & $\theta_{p e}$ & $\mathscr{R}_{12 s}(0)$ & $\theta_{s a 2}$ & $\theta_{s e}$ \\
\hline $\begin{array}{l}\mathrm{Ag}, N_{2}=0.05-j 2.87 \\
\quad(0.5 \mu \mathrm{m})\end{array}$ & $\begin{array}{l}1.5 \\
2.0 \\
3.0\end{array}$ & $\begin{array}{l}0.9637 \\
0.9626 \\
0.9626\end{array}$ & $\begin{array}{l}0.263 \\
0.237 \\
0.172\end{array}$ & $\begin{array}{l}0.26 \\
0.24 \\
0.17\end{array}$ & $\begin{array}{l}0.9801 \\
0.9736 \\
0.9695\end{array}$ & $\begin{array}{l}0.322 \\
0.663 \\
1.256\end{array}$ & $\begin{array}{l}0.32 \\
0.66 \\
1.26\end{array}$ \\
\hline $\begin{array}{l}\mathrm{Al}, N_{2}=0.64-j 5.497 \\
\quad(0.492 \mu \mathrm{m})\end{array}$ & $\begin{array}{l}1.5 \\
2.0 \\
3.0\end{array}$ & $\begin{array}{l}0.8561 \\
0.8422 \\
0.8118\end{array}$ & $\begin{array}{l}1.111 \\
1.072 \\
0.947\end{array}$ & $\begin{array}{l}1.11 \\
1.06 \\
0.94\end{array}$ & $\begin{array}{l}0.9178 \\
0.8814 \\
0.8349\end{array}$ & $\begin{array}{l}1.375 \\
3.141 \\
7.355\end{array}$ & $\begin{array}{l}1.37 \\
3.14 \\
7.34\end{array}$ \\
\hline $\begin{array}{l}\mathrm{Rh}, N_{2}=1.62-j 4.633 \\
\quad(0.564 \mu \mathrm{m})\end{array}$ & $\begin{array}{l}1.5 \\
2.0 \\
3.0\end{array}$ & $\begin{array}{l}0.6093 \\
0.5797 \\
0.5219\end{array}$ & $\begin{array}{l}3.789 \\
3.727 \\
3.558\end{array}$ & $\begin{array}{l}3.51 \\
3.36 \\
2.9\end{array}$ & $\begin{array}{l}0.7608 \\
0.6706 \\
0.5710\end{array}$ & $\begin{array}{r}4.448 \\
10.320 \\
25.247\end{array}$ & $\begin{array}{r}4.40 \\
10.05 \\
23.75\end{array}$ \\
\hline
\end{tabular}

a $N_{1}$ is the film refractive index, $N_{2}$ is the substrate complex refractive index at the indicated wavelength $\lambda . \mathcal{R}_{12 p}(0)$ and $\mathcal{R}_{12 s}(0)$ are the film-substrate intensity reflectances evaluated at exact grazing incidence $(\theta=0)$. $\theta_{p a 2}$ and $\theta_{s a 2}$ are the approximate polarizing angles calculated from Eqs. $(8)$ and truncated to three decimal places. $\theta_{p e}$ and $\theta_{s e}$ are the exact polarizing angles as determined by Ruiz-Urbieta and Sparrow. ${ }^{2}$ All angles are in degrees.

of a transparent film of refractive index that takes values from 1.2 to 4 on the same Al substrate $\left(N_{2}=1.212-j 6.924\right.$ at $\lambda=$ $6328 \AA$ ). The results are compared in Figs. 2 and 3 . The maximum absolute differences are $0.026^{\circ}$ for $\theta_{p}$ and $0.05^{\circ}$ for $\theta_{s}$. The curves of $\theta_{s e}$ and $\theta_{s a 2}$ appear coincident in Fig. 3 ; the maximum difference is $<0.5 \%$ in this case.

For reference, we have superimposed dashed curves upon Figs. 2 and 3 that represent other approximate polarizing angles, namely,

$$
\begin{aligned}
& \theta_{p a 1}=(45 / \pi) \frac{\left(N_{1}^{2}-1\right)^{1 / 2}}{N_{1}^{2}}\left[1-\mathcal{R}_{12 p}(0)\right], \\
& \theta_{s a 1}=(45 / \pi)\left(N_{1}^{2}-1\right)^{1 / 2}\left[1-\mathcal{R}_{12 s}(0)\right] .
\end{aligned}
$$

These are the first-order approximations to the polarizing angles obtained when the quadratic $\left(\theta^{2}\right)$ terms are dropped from Eqs. (6). They represent the situation in which the curves of $\mathscr{R}_{01 p}$ and $\mathscr{R}_{01 s}$ in Fig. 1 are replaced by their straight-line tangents at $\theta=0$ (instead of parabolas for the quadratic approximation). For the $\mathrm{Al}_{2} \mathrm{O}_{3}-\mathrm{Al}$ system at 6328 $\AA$, one obtains

$$
\theta_{p a 1}=1.215^{\circ}, \quad \theta_{s a 1}=1.953^{\circ} .
$$

The degree of match with the exact solution [Eqs. (10)] is an order of magnitude worse for the linear approximation [Eqs. (13)] than it is for the quadratic approximation [Eqs. (9)]. Only when the substrate reflectance is very high $(>95 \%)$ can the linear approximation be useful.

The quadratic approximation is far superior and is the one to use. The simplification in going from Eqs. (8) to Eqs. (12) is too slight to justify paying further attention to the linear approximation.

We also compared the $p$ - and $s$-polarizing angles calculated from our approximate Eqs. (8) with those (exact) angles obtained numerically by Ruiz-Urbieta and Sparrow. ${ }^{2}$ Table 1 gives results for the two high-reflectance metals $\mathrm{Ag}$ and $\mathrm{Al}$ (normal-incidence reflectances $\mathcal{R}_{0}=97.9 \%$ for $\mathrm{Ag}$ and $92.2 \%$ for $\mathrm{Al}$ at $\lambda=0.5$ and $0.492 \mu \mathrm{m}$, respectively) and for film refractive indices of 1.5, 2.0, and 3.0. Again, our approximate explicit equations [Eqs. (8)] yield results that agree with the exact numerical data of Ruiz-Urbieta and Sparrow to within $\sim 0.01^{\circ}$ for these metals and films.
To test the range of validity of Eqs. (8), Table 1 compares our approximate polarizing angles with the exact ones of Ref. 2 for the low-reflectance metal $\mathrm{Rh}\left(R_{0}=77.1 \%\right.$ at $\lambda=0.564$ $\mu \mathrm{m})$. Poorer agreement is obtained, as expected. The disagreement becomes more pronounced as the reflectances $\mathcal{R}_{12 \nu}(0)$ approach 0.5 , the lowest limit of validity of our approximate equations.

Finally, we should mention that Eqs. (8) continue to hold when the metal substrate is replaced by a high-reflectance multilayer substructure. In this case, $\mathscr{R}_{12 \nu}(0)$ represents the reflectance of the film-substructure interface at external grazing incidence $(\theta=0)$ for the $\nu$ polarization.

\section{ACKNOWLEDGMENTS}

I thank Karim Javily and Tracy Thonn for their assistance with the numbers and figures. The support of the State of Louisiana Board of Regents and the Foundation for A Better Louisiana is gratefully acknowledged.

\section{REFERENCES}

1. J. M. Bennett and H. E. Bennett, "Polarization," in Handbook of Optics, W. G. Driscoll and W. Vaughan, eds. (McGraw-Hill, New York, 1978), in particular p. 10-100.

2. M. Ruiz-Urbieta and E. M. Sparrow, "Reflection polarization by a transparent-film-absorbing-substrate system," J. Opt. Soc. Am. 62, 1188-1194 (1972).

3. The Fresnel-interface reflection coefficients are given in many optics books (e.g., Ref. 1) and will not be reproduced here.

4. T. H. Allen, "Study of Al with combined auger spectrometer-ellipsometer system," J. Vac. Sci. Technol. 13, 112-115 (1976).

5. H. Kitajima, K. Fujita, and H. Cizmic, "Zero reflection from a dielectric film on metal substrate at oblique angles of incidence," Appl. Opt. 23, 1937-1939 (1984).

6. R. M. A. Azzam, "Grazing-incidence differential-reflectance method for explicit determination of the complex dielectric function of an isotropic absorbing medium," Rev. Sci. Instrum. 54, 853-855 (1983).

7. We followed the procedure described by R. M. A. Azzam, A.-R. M. Zaghloul, and N. M. Bashara, "Ellipsometric function of a filmsubstrate system: applications to the design of reflection-type optical devices and to ellipsometry," J. Opt. Soc. Am. 65, 252-260 (1975). 